Supplement of Atmos. Chem. Phys., 17, 5379-5391, 2017

http://www.atmos-chem-phys.net/17/5379/2017/

doi:10.5194/acp-17-5379-2017-supplement

(C) Author(s) 2017. CC Attribution 3.0 License.

(c) (i)
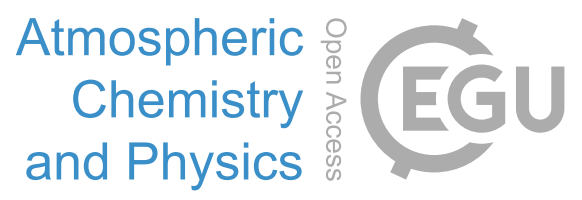

Supplement of

\title{
Long-term particulate matter modeling for health effect studies in California - Part 2: Concentrations and sources of ultrafine organic aerosols
}

\section{Jianlin Hu et al.}

Correspondence to: Jianlin Hu (hu_jianlin@ 126.com, jianlinhu@ nuist.edu.cn) and Michael J. Kleeman (mjkleeman@ucdavis.edu)

The copyright of individual parts of the supplement might differ from the CC-BY 3.0 licence. 
3 Equations:

$4 \quad$ MFB and MFE are calculated using equation S1 and S2, respectively.

$$
\begin{gathered}
M F B=\frac{1}{N} \sum_{i=1}^{N} \frac{\left(C_{m}-C_{o}\right)}{\left(\frac{C_{o}+C_{m}}{2}\right)} \\
M F E=\frac{1}{N} \sum_{i=1}^{N} \frac{\left|C_{m}-C_{o}\right|}{\left(\frac{C_{o}+C_{m}}{2}\right)}
\end{gathered}
$$

7 The PM model performance criteria of MFB and MFE, suggested by Boylan and Russell (2006), 8 are a function of PM concentration as follows:

11 Where Co and Cm in S1-S4 represent the observed and predicted PM concentrations,

12 respectively.

\section{Tables and Figures:}

14 Figure S1: Predicted 9 year average $\mathrm{PM}_{2.5}$ Total OA concentration and SOA/TOA ratio in 15 California

16 Figure S2: $\mathrm{PM}_{2.5}$ SOA concentrations formed from different precursors.

17 Figure S3: Emission of different sources of long alkanes and aromatics in the "other 18 anthropogenic" source category.

19 Figure S4: Monthly source contributions to $\mathrm{PM}_{2.5}$ SOA at 6 urban sites.

20 Figure S5: Predicted source contributions to 9 year average $\mathrm{PM}_{2.5}$ POA concentrations.

21 Figure S6: Predicted source contributions to 9 year average $\mathrm{PM}_{2.5}$ SOA concentrations.

22 Figure S7-S11: Influence of accounting for vapor wall losses on SOA results for SOA derived 23 from long alkanes (S1), aromatics (S2), isoprene (S3), sesquiterpenes (S4), and monoterpenes 24 (S5). 

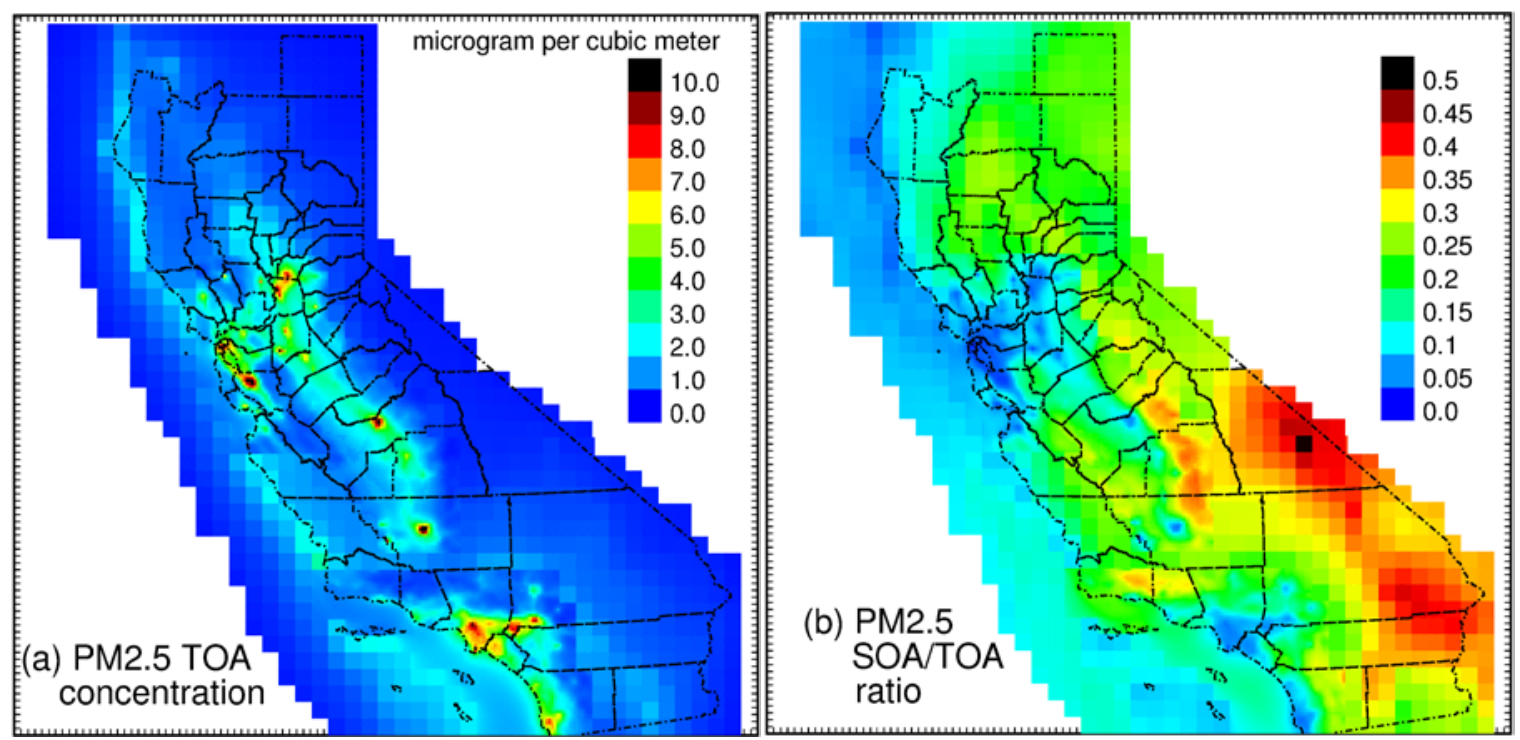

27 Figure S1. Predicted 9-year average (a) $\mathrm{PM}_{2.5}$ Total OA (TOA) concentrations and (b) $\mathrm{PM}_{2.5}$

28 SOA/TOA ratios in California. Natural sources including windblown dust contribute more to the $29 \mathrm{PM}_{2.5}$ size fraction than the $\mathrm{PM}_{0.1}$ size fraction in remote regions at the northeast and southeast 30 corners of the state, which explains the different behavior illustrated in Figure 4 and Figure S1. 

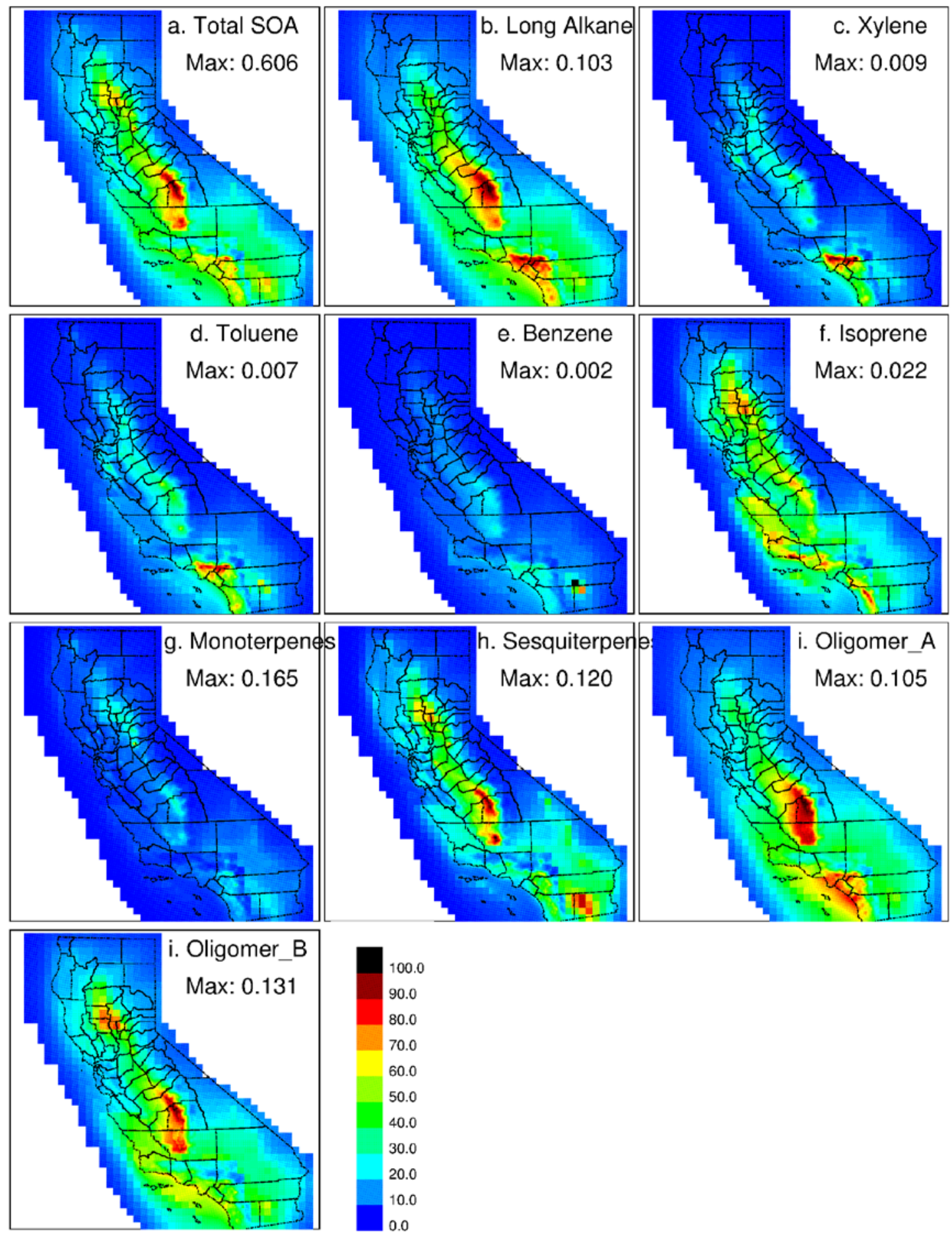

33 Figure S2. (a) 9-year average SOA concentrations; and SOA formed from (b)AALK, (c) AXYL, 34 (d) ATOL, (e) ABNZ, (f) AISO, (g) ATRP, (h) ASQT, (i) AOLGA, and (j) AOLGB in PM 2.5 . 35 The color scales (shown in the last panel in unit of \%) indicate the ratio of the concentrations to 36 the max concentration values. The maximum concentration values are shown in the panels under 37 the names of the species, with a unit of $\mu \mathrm{g} / \mathrm{m}^{3}$. 

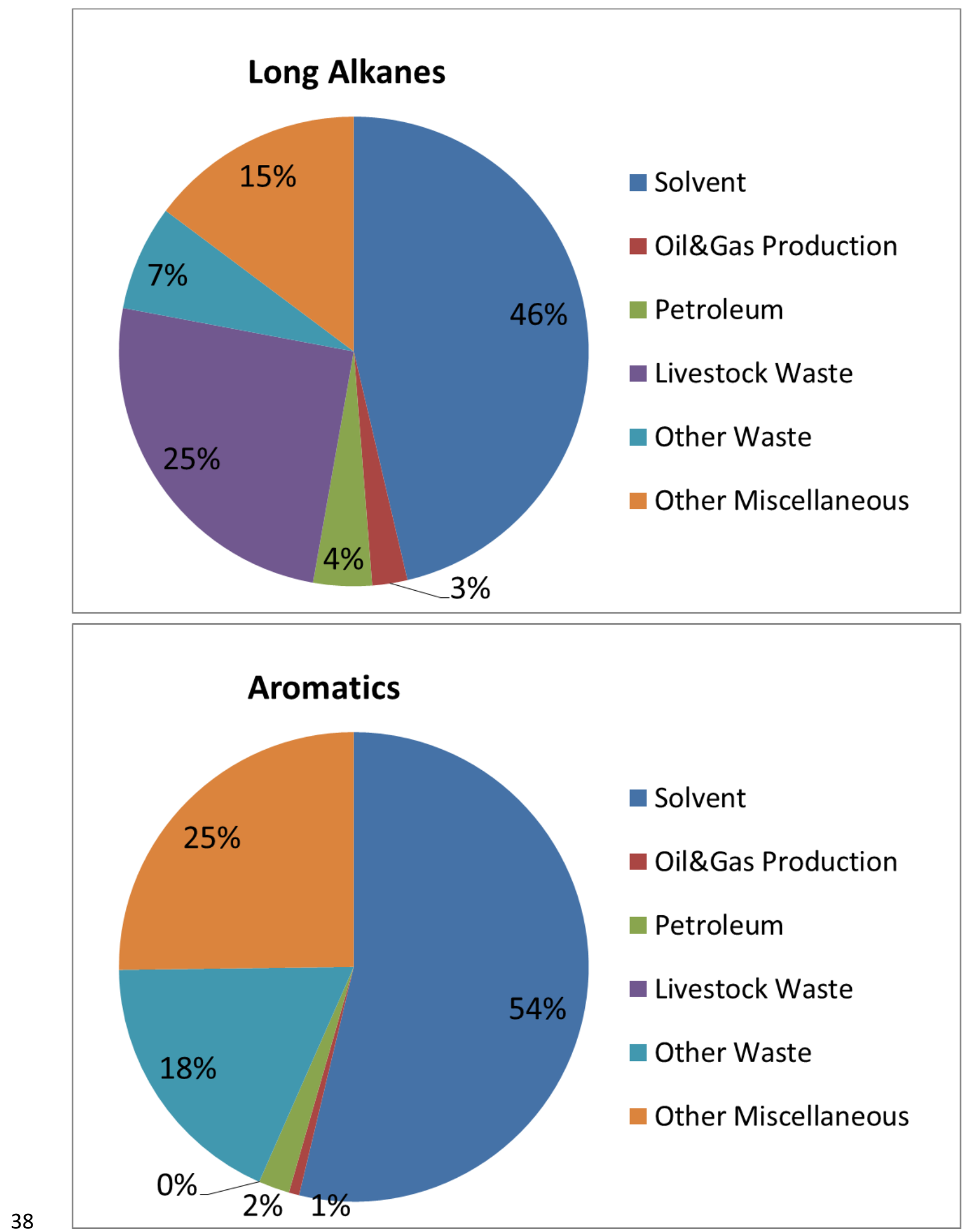

39 Figure S3. Emission of different sources of long alkanes and aromatics in the "other 40 anthropogenic” source category. 

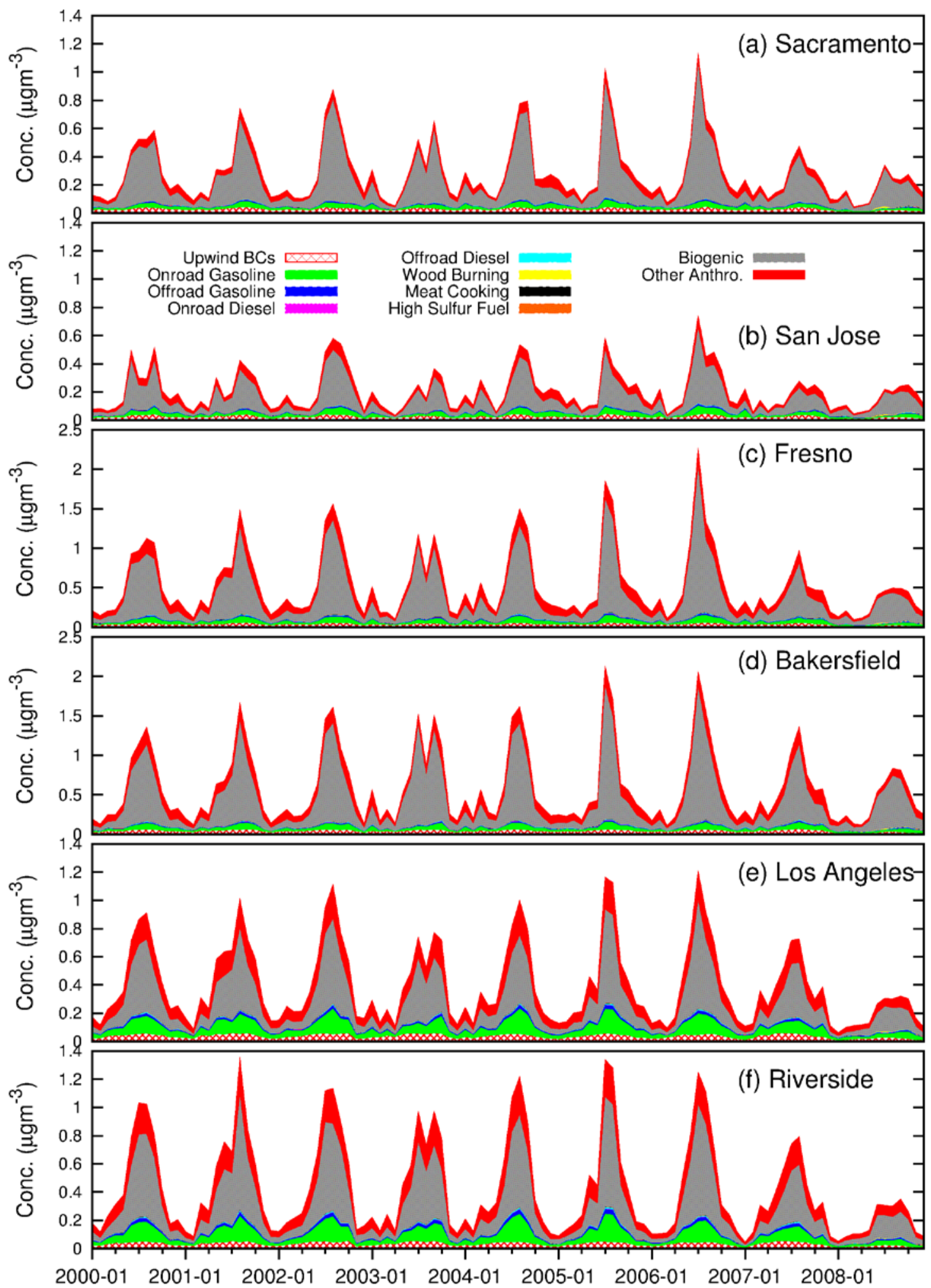

Figure S4. Monthly source contributions to $\mathrm{PM}_{2.5} \mathrm{SOA}$ at 6 urban sites. Predicted SOA

43 concentrations from different sources are indicated by the colored areas. 

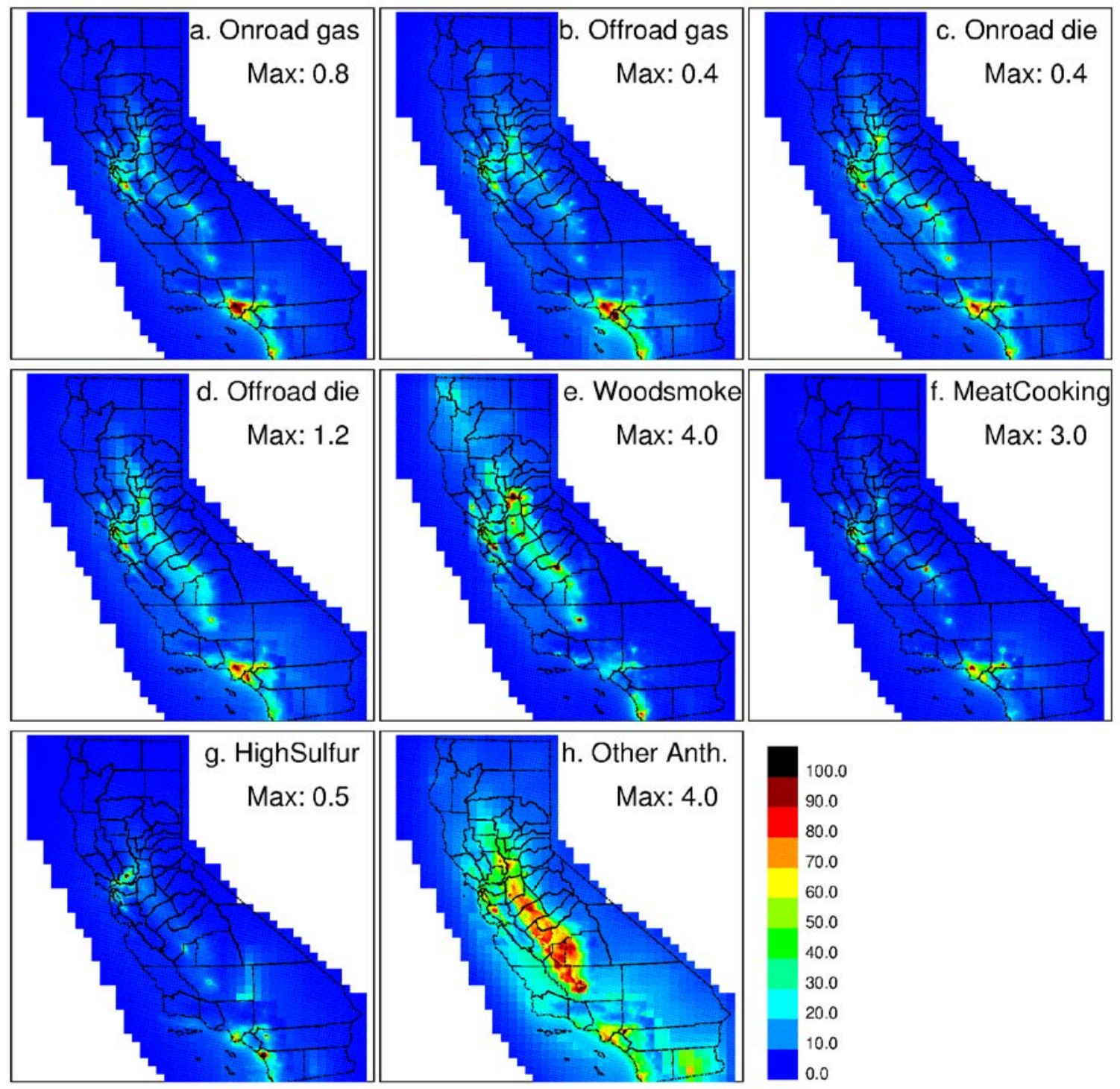

45

Figure S5. Predicted source contributions to 9 year average $\mathrm{PM}_{2.5}$ POA concentrations. The definition of the color scales are the same as in Figure 5. 

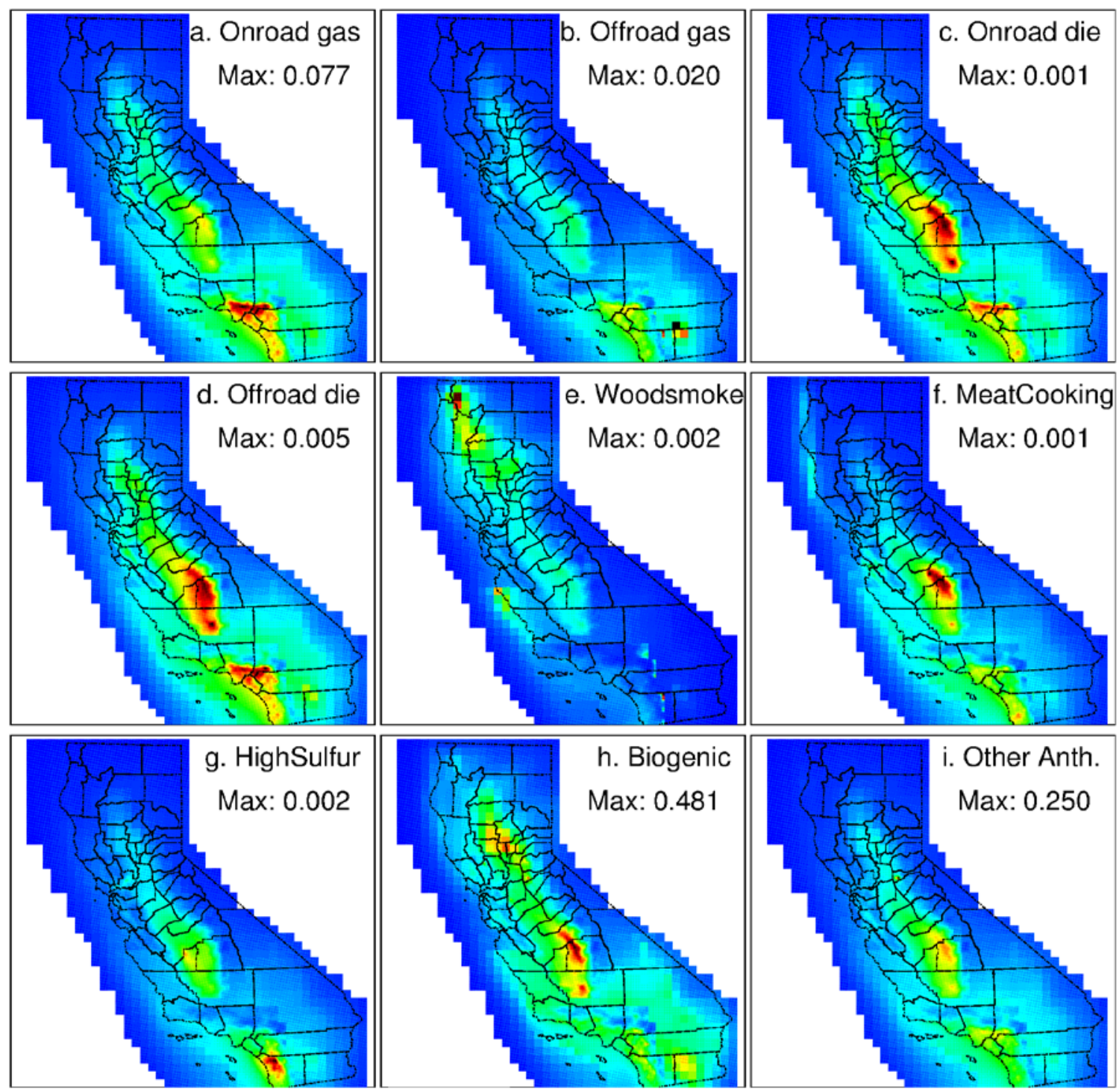

49 Figure S6. Predicted source contributions to 9 year average $\mathrm{PM}_{2.5}$ SOA concentrations. The 50 definition of the color scales are the same as in Figure 5. 

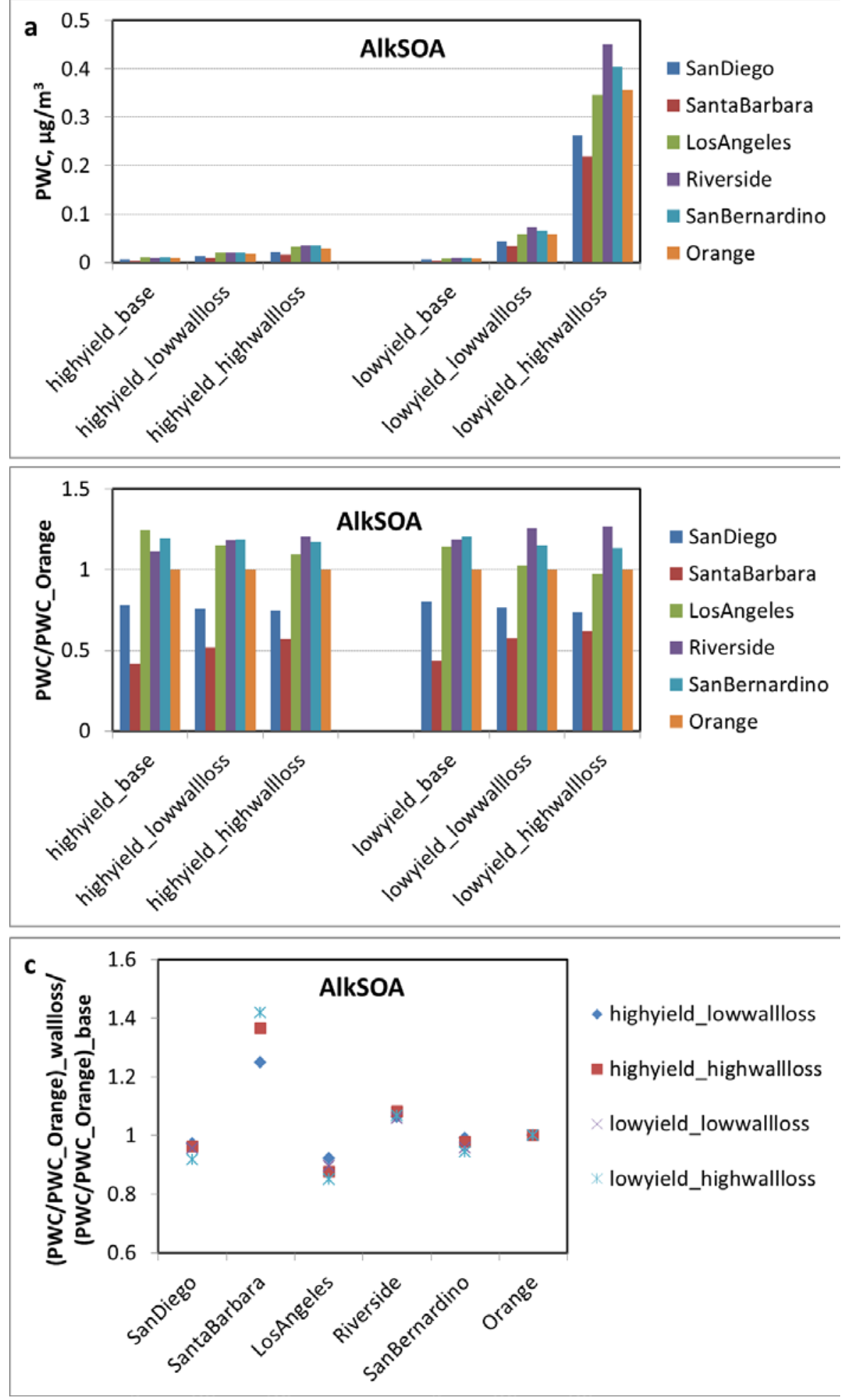

53 Figure S7 Same as Figure 9, but only for SOA derived from long alkanes (AlkSOA). 

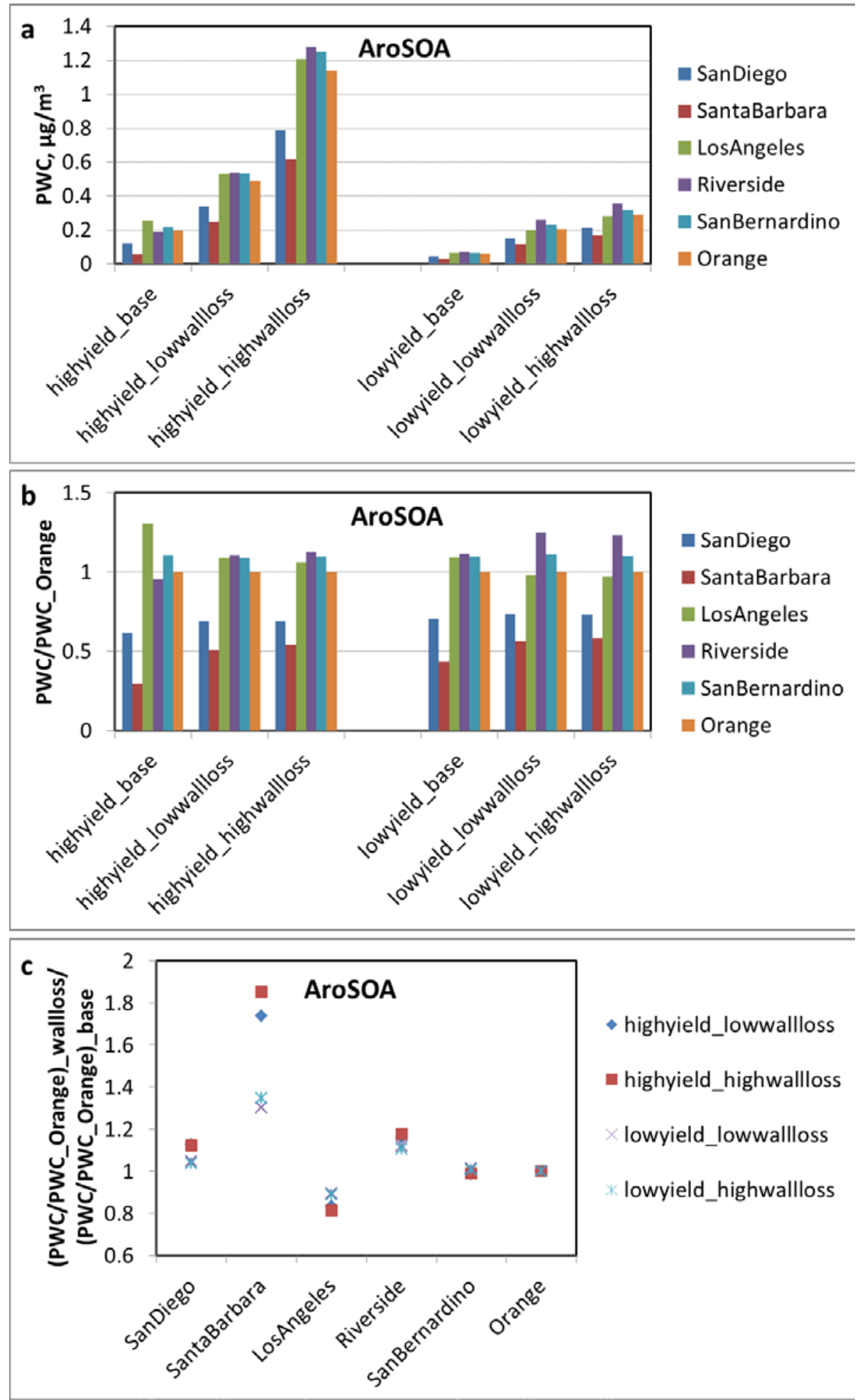

56 Figure S8. Same as Figure 9, but only for SOA derived from aromatics (AroSOA).

57 

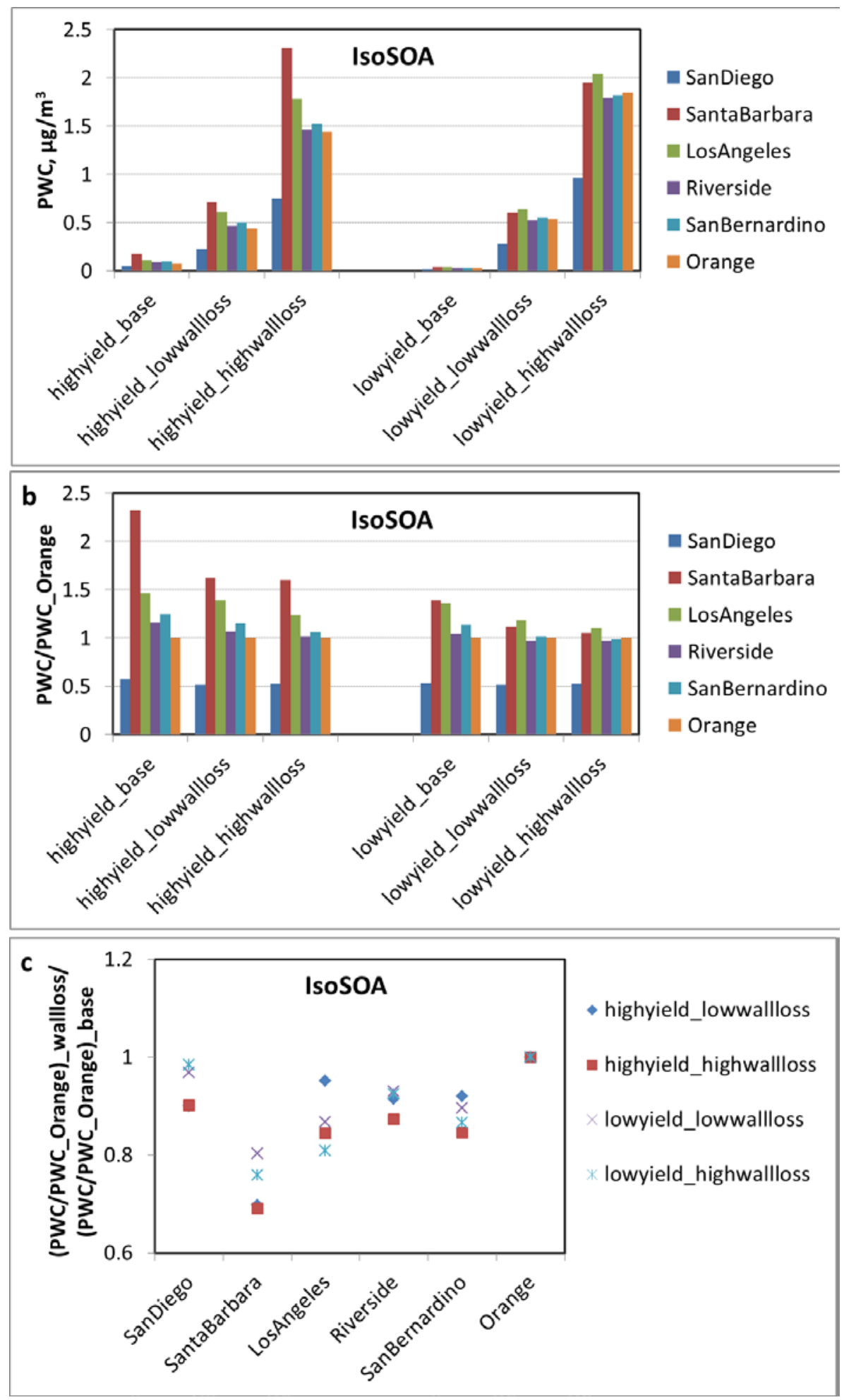

59 Figure S9. Same as Figure 9, but only for SOA derived from isoprene (IsoSOA).

60 

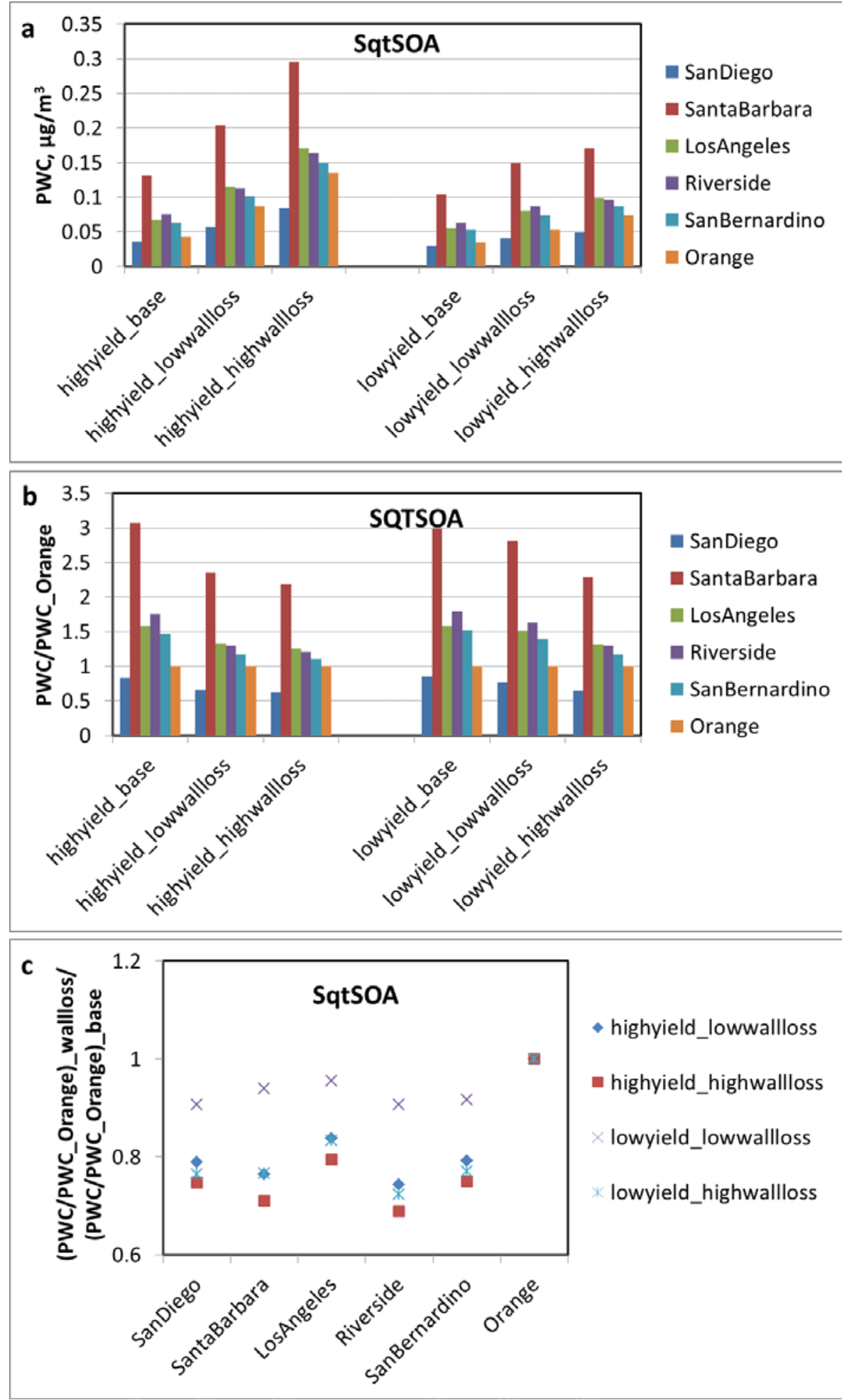

62 Figure S10. Same as Figure 9, but only for SOA derived from sesquiterpenes (SqtSOA). 

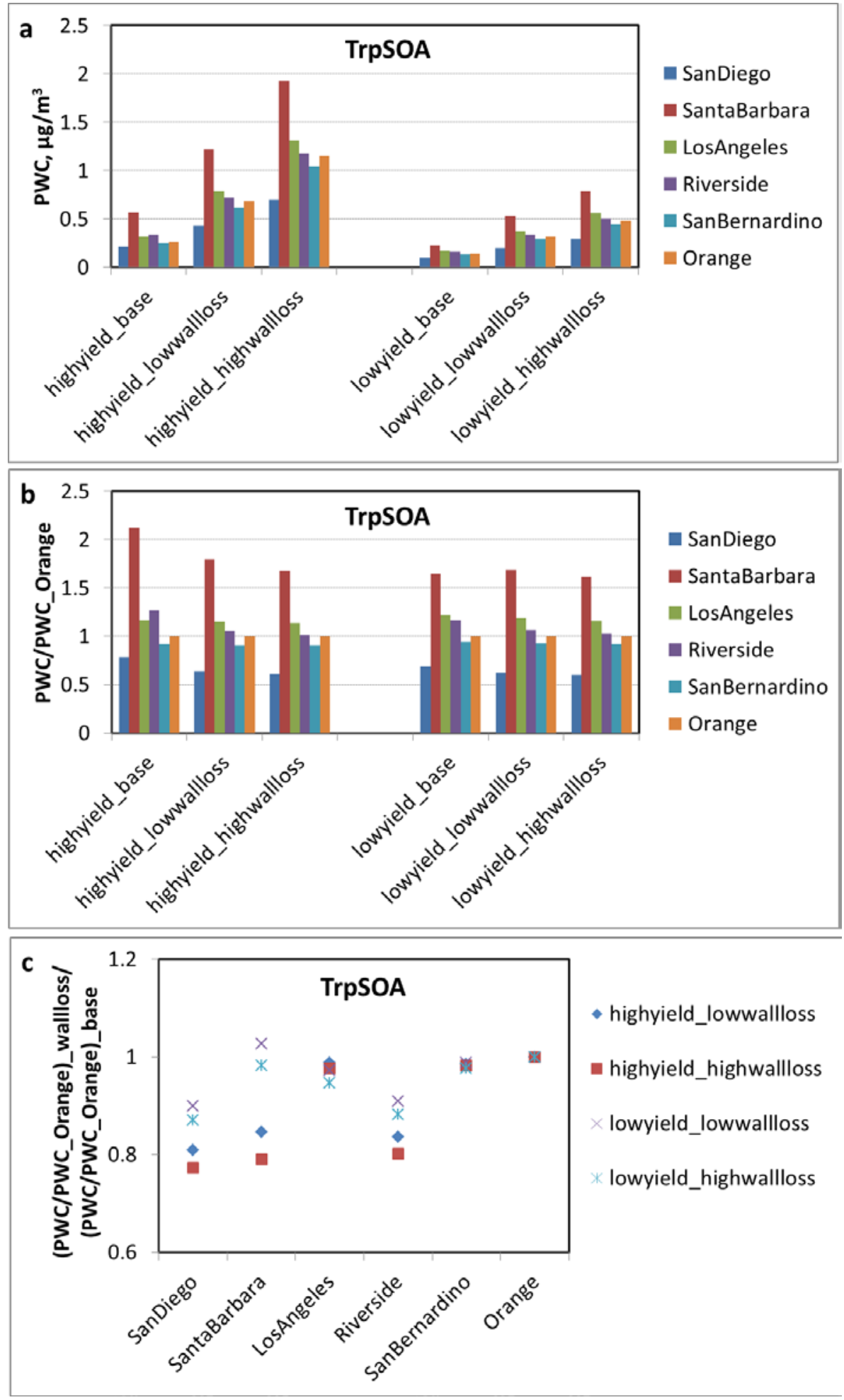

65 Figure S11. Same as Figure 9, but only for SOA derived from monoterpenes (TrpSOA). 